\title{
SITE LAYOUT PLANNING THROUGH BIM VISUALISATION - A CASE STUDY
}

\author{
Paramjit Singh Lota ${ }^{1}$, and Jyoti Trivedi ${ }^{2}$
}

\begin{abstract}
Site layout planning is a critical factor for the successful execution of any construction project. As cities develop, site logistics becomes an essential planning aspect for any construction project. Project sites in tight neighbourhoods lead to not just space constraints but also challenges to approach, material handling, and pollution control. Site layout planning has been in practice in the industry, however, limited to a traditional approach of a pre-construction assignment, rather than a dynamic system to analyse construction sites in terms of both space and time. Material handling and delays related to waiting for materials add to a considerable amount of waste during the execution of projects. The paper here explores minimisation of wastes on construction sites, as defined by Lean Construction, using a BIM model highlighting the construction site layout planning to visualise the various aspects of space constraints, access routes, safety considerations, and a visual approach to progress monitoring and reporting. The research follows a case study analysis to develop an understanding of the present scenario, based on which a proposed scenario has been developed to elaborate on the improvements. The paper concludes with a summary of wastes observed and minimised, along with benefits observed through BIM implementation.
\end{abstract}

\section{KEYWORDS}

Lean construction, site layout planning, site logistics, building information modeling (BIM), and BIM visualisation.

\section{INTRODUCTION}

Site layout planning is traditionally done to highlight the various areas of logistics required for the construction works to be executed on site, with an idealistic approach of only space constraints. Further, a 2D representation of the site limits the understanding of the project team to the complications arising with the development of the project on site. Improper planning can lead to tremendous wastes in terms of unnecessary transport of materials and other resources around the site (Singh \& Delhi, 2018). Material logistics planning is

1 Masters Student, M.Tech. Construction Engineering and Management, Faculty of Technology, CEPT University, Ahmedabad - 380009, India, +919619057645, paramjit.lota.mcem17@cept.ac.in

2 Assistant Professor, Faculty of Technology, CEPT University, Ahmedabad - 380009, India, +919925009609, jyoti@cept.ac.in 
essential for efficient project delivery, supporting lean construction by reducing unnecessary transportation and material handling, which are regarded as wastes (Cheng \& Kumar, 2015).

Lean Construction conceptualises "wastes" as hidden in construction processes. Rework due to design or construction errors, and non-value adding activities in the material and workflows, such as waiting, moving, inspecting, duplicated activities, and accidents are highlighted as the factors creating inherent waste on construction site (Koskela, 1992). Waste minimisation, enabled by Lean Construction, is driven by the primary goal to reduce non value-added time in construction processes. Further, it is also essential to make the wastes visible to the project team. This is where visualisation through BIM is proposed to enable all stakeholders to commonly develop an understanding of the site constraints and the supporting processes.

Construction projects in cities, as part of rapidly growing urban centres, have critical space constraints, with several projects coming up in densely packed residential areas, thereby adding to constraints of working hours, pollution and approachability. A number of these projects are now depending on supplied RMC through Transit Mixers for concrete, instead of providing for on-site concrete batching plants due to space limitations on site. Thus, the activity of concreting, a primary activity of typical construction projects, becomes extremely critical for such sites. Such project sites require extensive planning to factor in the lead time for concrete delivery based on the vendor's location, vis-à-vis the scheduled activity of concreting on site. Numerous projects plan activities such that multiple elements of concreting are sequenced to be carried in one go, in accordance with the amount of concrete being supplied by the Transit Mixture.

Singh and Delhi (2018) proposed an AR-BIM model tool for site layout planning, expecting to minimise construction wastes on site. However, the tool was in the development phase and hence, not implemented yet. Though a similar approach has been applied here, the authors, in this case, have developed a BIM model of the existing site layout of a project currently under execution. Based on the visualisation provided by this BIM model, the authors have developed a proposed site layout BIM model to enable minimisation of wastes on the site. Further, the various aspects of the construction activities on site have been analysed for highlighting the various observed. The BIM enabled visualisation of the project site layout is proposed as an essential planning factor prior to the execution of the project.

\section{LITERATURE REVIEW}

Pikas et al. (2011) highlight the importance of visualisation in enabling project teams to develop a shared understanding of the project. This is further backed by Dave et al. (2013) stating the benefits of visualisation to scheduling. Such mutual understanding, when developed for site layout planning prior to execution works commencing on site, can enable the generation of flow through minimised wastes during construction activities. Guerriero et al. (2017) suggest how virtual 4D planning, through an IPD approach by gaining constructability information from the Contractor, can enable modeling of temporary structures and management of tight site conditions. This makes the early involvement of 
stakeholders essential for pre-construction activities, enabling better planning for the execution on site.

The fact that Lean Construction and BIM have positive synergies has been well established by Sacks et al. (2010). This is further reinforced by Fosse et al. (2017) by stating the benefits observed by several contractors by integrating both Lean and BIM in construction projects. Multiple authors have highlighted the similarities in working principles and the importance of BIM and Lean integration for projects to reap Lean efficiency gains and reduce wastes in their processes (Gerber et al. 2010; Guerriero et. al. 2017). Sacks et al. (2010) elaborate on the fact that though cycle time is reduced by BIM, the comprehensive benefits can only be achieved when its meaning is perceived clearly, thereby supporting the integration of Lean and BIM.

BIM-based constructability analysis contributes to Lean and green outcomes, as highlighted by Ahuja et al. (2016) in their case study of green Indian projects. The factors enabling this have been identified as reduction of rework, minimisation of errors, and improved productivity and performance.

However, despite the benefits of BIM and Lean Construction and their integration on projects, BIM implementation has been limited to the design phase of the project (Jin et al. 2017), and to some extent to the construction phase (Pikas et al. 2011). An exploration into BIM use for site layout planning is generally overlooked. The literature review highlights a limited exploration into the development of a BIM model for site layout planning.

Bortolini et al., 2015 explores the planning and controlling of logistics processes with the use of 4D BIM modeling. The paper studies the use of BIM to simulate both valueadding and non-value-adding activities, such as waiting, inventory and moving materials, as well as site layout. However, the case explored was in context of engineer-to-order prefabricated building system, devoid of several site constraints related to space, access, and safety.

The paper here aims to address this gap by understanding the site layout constraints of a typical construction project in India and reducing wastes observed by the visualisation enabled through the BIM model developed.

\section{RESEARCH METHODOLOGY}

The research aims to understand the importance of site layout planning to minimise wastes observed on construction site and add value to the project through collaborative planning, by visualisation through BIM models developed for the site layout of the project.

The paper adopts a case study approach of commercial development in an urban city in India. The project was studied over a period of three months, during which the BIM model of the existing site layout was developed based on extensive documentation and site visit by the authors. The proposed site layout BIM model was developed based on the understanding of the processes of construction activities documented over these visits.

The work is supported by direct observation and interaction with the project teams. The interactions were essential to understanding the processes linked to the construction activities being executed on site, and the challenges and limitations faced. Observations 
over the various site visits enabled a real-time understanding of the nuances of these constraints, that were generally overlooked during the interactions with the project team.

\section{SITE LAYOUT PLANNING CASE STUDY}

The project under study is a $\mathrm{G}+13$ commercial development project with 3 Basement levels, currently under execution at the $8^{\text {th }}$-floor roof slab level. Located in a rapidly developing city in India, the project is proposed to house retail stores and office spaces. The BIM model was developed during the execution phase, providing an understanding of the limitations of the current site layout vis-à-vis the activities being executed on site, based on which a proposed layout was developed to overcome the observed limitations.

\section{EXISTING SITE LAYOUT BIM MODEL}

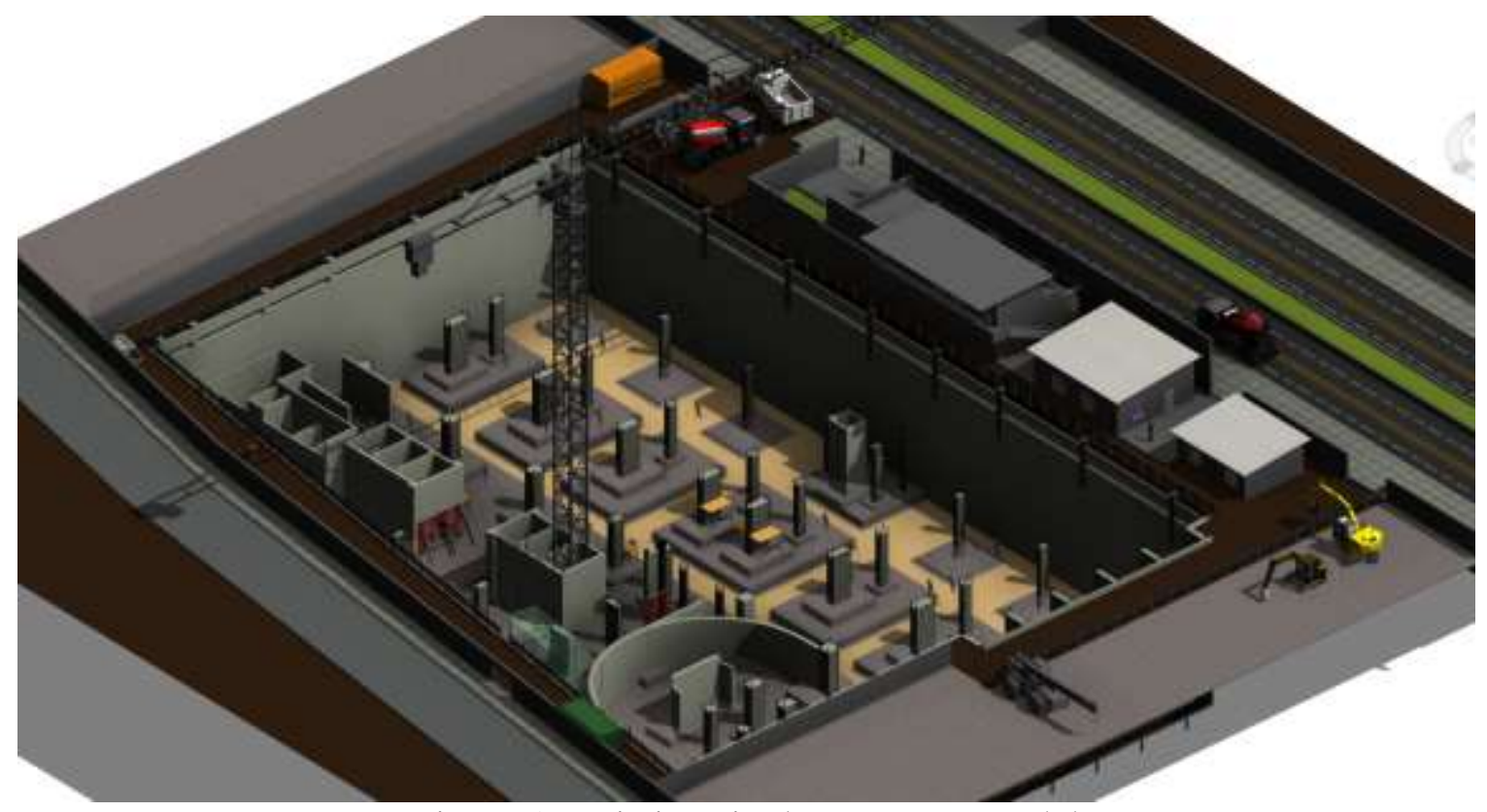

Figure 1: Existing site layout BIM model

The BIM model was developed using the drawings provided by the Project team, along with multiple site visits to understand the existing layout in terms of space, material and equipment logistics. A detailed model was developed based on a thorough understanding of the on-going activities on site, and the processes enabling them. Figure 1 shows the existing site layout BIM model. The image shown here is of the model progressively developed along with active participation with the project team. The model tracked the activities from excavation to now showing the foundation work that was being executed on site. The dynamic development of the model enabled the team to further pull BIM for various discussions concerning the planning of activities being executed on site.

The existing site layout model shows the location of the various components on site, including the sales office, site offices, stores, material un-loading points and the various equipment being used on the project site. The same has been highlighted in Figure 2. 


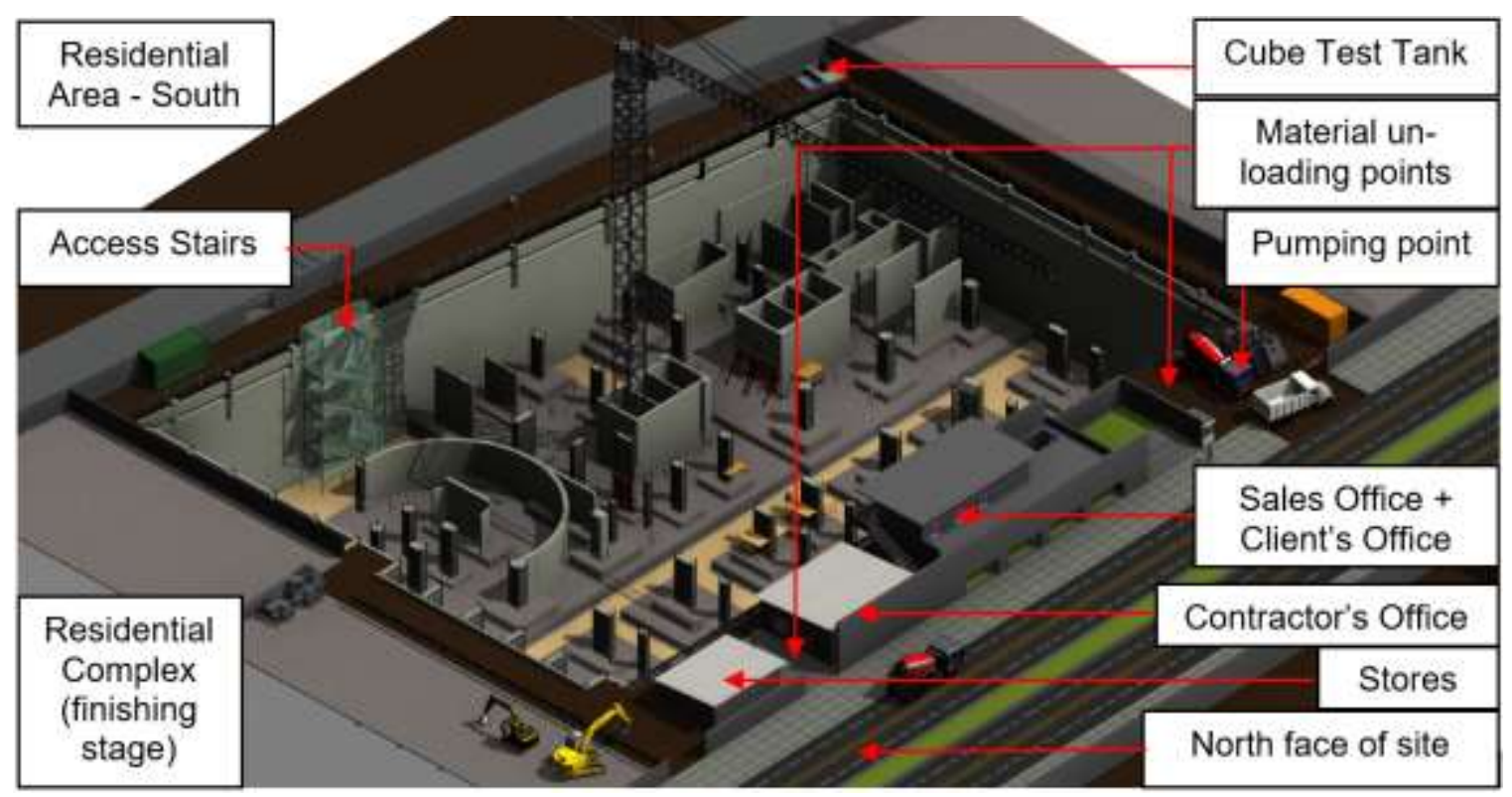

Figure 2: Exiting site layout BIM model highlighting the various site components

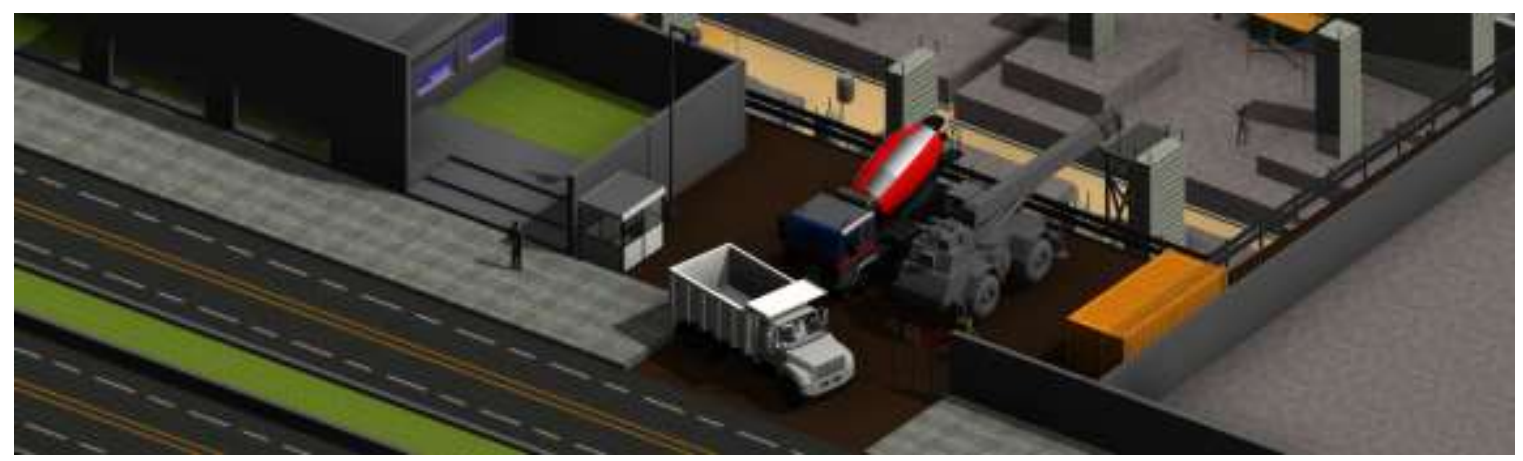

Figure 3: Primary material un-loading and concrete pumping point

\section{SITE LAYOUT ANALYSIS}

The site is located on the main road. To the west of the site, there is a storage depot while to the east is a residential complex under construction (finishing stage). To the south is a by-lane leading to the dense residential neighbourhood (Figure 2).

The project site is adjoining built plots on either side. The direct and most accessible side is to the North of the site, i.e. the main road. This side becomes the most crucial for all construction operations on site. The sales office, site offices, stores, material un-loading points as well as concrete pumping points are all housed on this side (Figure 3 ).

\section{Key limitations of the existing site layout}

Based on various site visits, several limitations have been critically observed on site. The primary limitation is of space constraint, due to which storage of material and equipment is very poorly managed on site. A lot of material is observed lying around at various locations on site, making the access unsafe. The barricade to ensure fall-protection is 
damaged at various parts on site. At various parts, the site-team is expected to walk over temporarily store rebars on site, making the access further unsafe.

The second key limitation is the access constraint to site. The limited frontage available at the north face towards the main road for receiving material and RMC leads to excessive crowding of transporters on site; trucks and Transit Mixers. This leads to excessive waiting at times, due to the limited organisation of space to house the transporters. Further, transporters occupy parts of the footpath for waiting, thereby increasing the responsibility of cleanliness and maintenance of the same by the project team, adding to extra work.

The cube testing curing tank present on site is located at the far southwest end. Samples prepared at the unloading area to the north are taken all the way for curing of the Cube test samples. Presently there is no dedicated quality testing lab on site.

Unloading of materials, deployment of equipment by mobile crane, preparation of cube-test samples, pumping of concrete, etc. are some activities which raise critical safety and quality concerns in practice.

\section{PROPOSED SITE LAYOUT BIM MODEL}

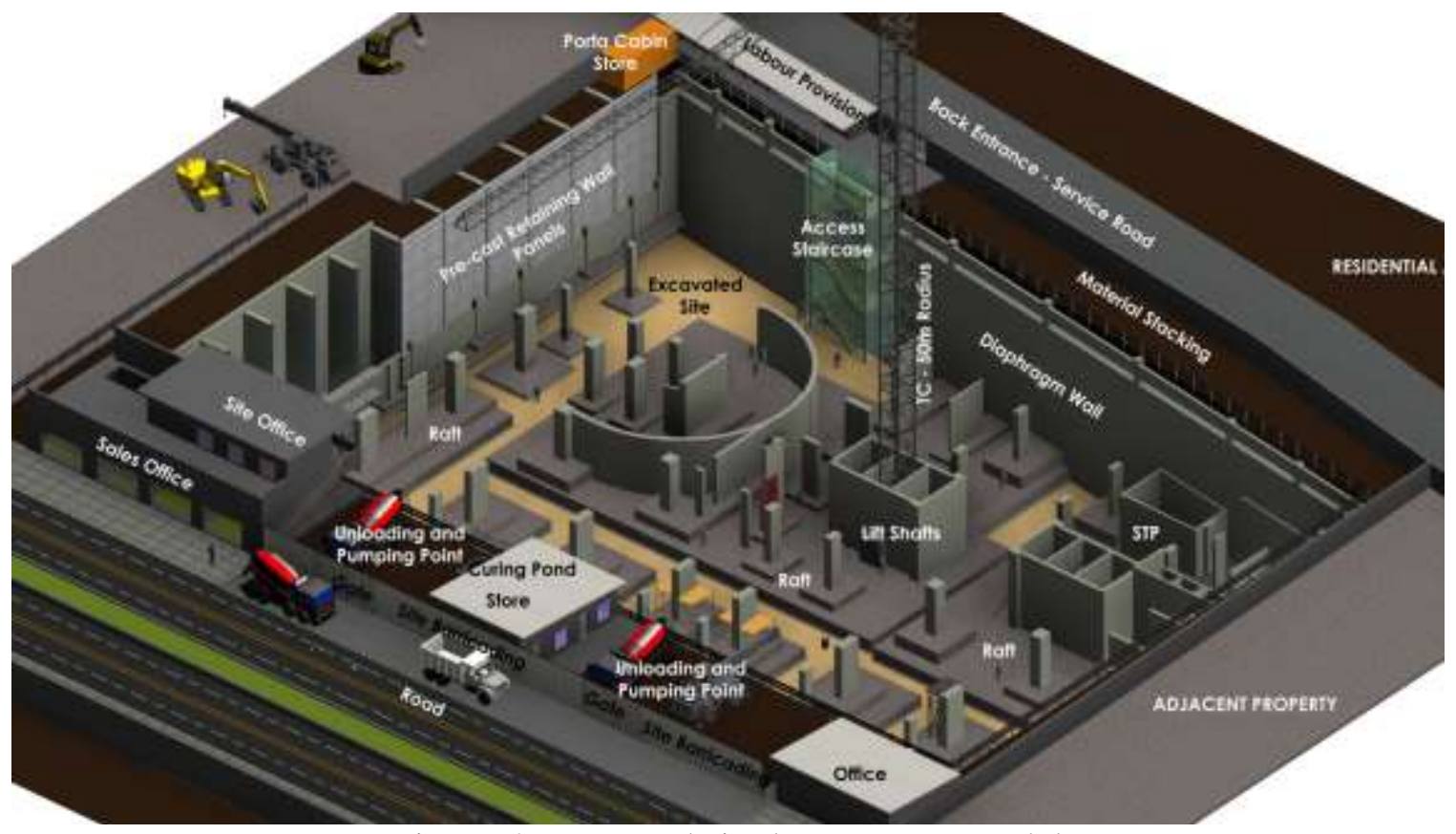

Figure 4: Proposed site layout BIM model

Construction Site layout planning is done by identifying, sizing, and placing all the facilities, safely and efficiently, within the boundaries of the construction site. The issues identified with the existing site layout have been addressed here.

The proposed site layout model has been developed (Figure 4) considering how the planning could have been done for locating the Sales \& Site offices, Quality Lab \& Material Store, and the labour provisions. The sales office has been moved to the N-E corner of the site, thereby clearing out maximum space for the concrete pumping and material unloading points. The provision of two points will ensure complete coverage of concreting works for 
the site. Further, the centrally located Store \& Material testing lab ensures minimum movement of material around the site (Figure 5).

Safety barricading has been proposed on the main-road facing side of the site, with dedicated access gates for parking the transporters and other heavy equipment, thereby creating a safer environment on site. Labour provisions have been provided next to the access staircase with appropriate sheltering and toilets for the convenience of the labour workforce operating on site. Clear area has been demarcated for material stacking at the south side, creating a sense of organisation and order in the site layout.

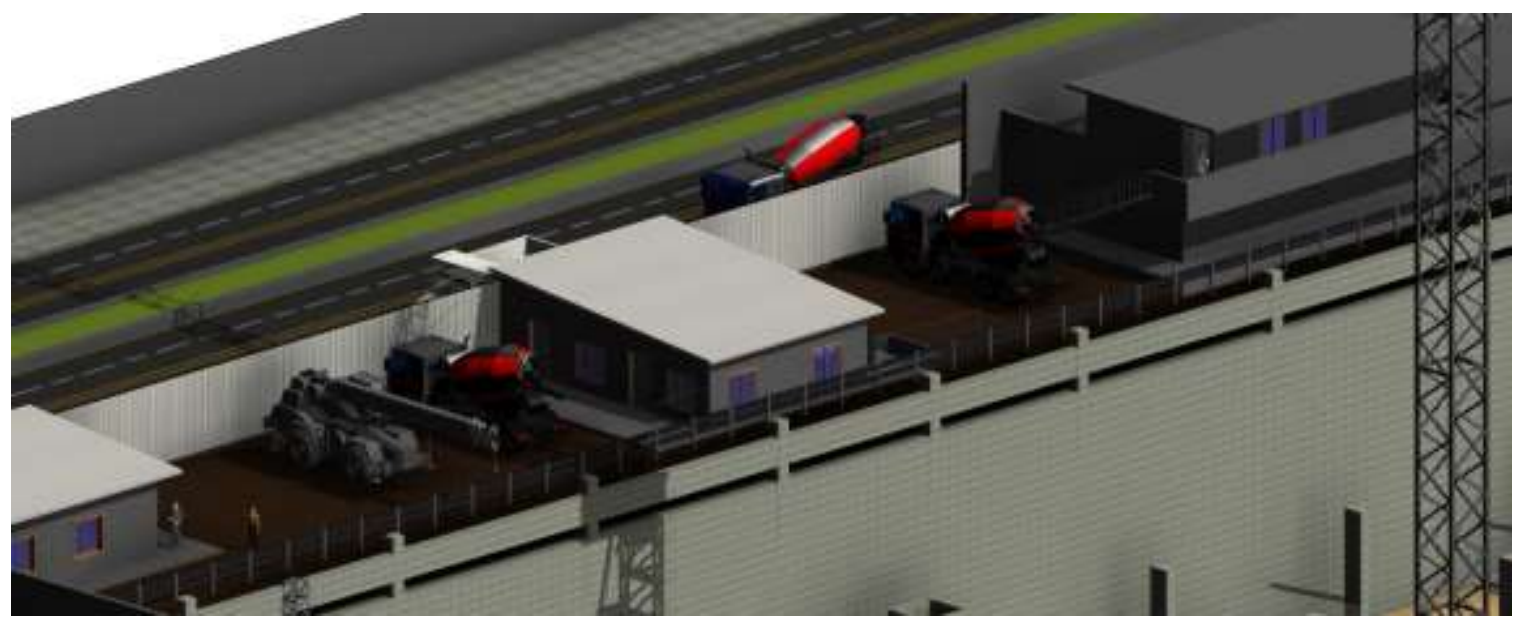

Figure 5: Proposed central store and quality testing lab

As discussed repeatedly, the site location is such that site boundary is extremely close to the building perimeter. The storage area is limited, and concrete can be pumped from only one side of the site. Due to space constraints on site, judicious use of access points for construction activities is a must, based on which the proposed layout has been developed. By proposing two unloading points, an attempt has been made to minimise wastes by reduction of waiting time, increase flow by mobility of equipment and labour, and generation of value by providing a safer and organised environment for activities on site. The simultaneous use of two points for pumping of concrete would enable minimum waiting and allow for concreting activities to complete sooner. Though the logistics requirement would also increase to enable the same (more manpower, two concrete pumps, etc.), the potential of such a scenario is possible and critically important for such sites, wherein space constraints are a major hindrance to the execution of the project.

To illustrate a more practical scenario, the team could enable the two points by using one for concreting of slab pours using a single concrete pump, while the other unloading point could be simultaneously used for the casting of vertical members using a concrete bucket and the tower crane on site. This would considerably reduce the waiting time of activities.

\section{Importance of early involvement of stakeholders}

The exploration through BIM visualisation done for this research is brought about by the essential requirement of early involvement of stakeholders, driven by the principles of Integrated Project Delivery (IPD). BIM enables IPD, and the fact that such site layout 
modeling is possible stands to show the need for involving contractors at the right stage of project planning to enable efficient execution of construction activities. The case study here highlights the crucial requirement of providing frontage to the side at the access from the main road, wherein the sales office was developed by the Client before the Contractor was mobilised on site. This location has proved to be of inconvenience for the Contractor to set up the required infrastructure and execute the activities on site. With early involvement, such collaboration would enable discussion through visualisation provided by BIM models, that can help teams to be better prepared for the execution stage.

\section{Summary of wastes observed and minimized in the site layout planning}

The table below (Table 1) highlights the summary of wastes, as defined by Lean, observed and minimised through appropriate planning of the proposed site layout. The visualisation offered by BIM was observed to enable discussion on these between the project team.

Table 1: Summary of wastes observed and minimized through the proposed site layout

\begin{tabular}{|c|c|c|c|}
\hline $\begin{array}{l}\text { S. } \\
\text { No. }\end{array}$ & $\begin{array}{l}\text { Waste } \\
\text { Identified }\end{array}$ & Existing Site Layout & Proposed Site Layout \\
\hline 1. & $\begin{array}{l}\text { Waiting, } \\
\text { Overproduction, } \\
\text { Transportation }\end{array}$ & $\begin{array}{l}\text { Inappropriate location of sales } \\
\text { office leading to space constraints } \\
\text { for loading \& unloading of material } \\
\text { and pumping of concrete. }\end{array}$ & $\begin{array}{l}\text { Relocated to the corner of the } \\
\text { site, in order to clear out } \\
\text { maximum usable space in the } \\
\text { centre for construction activity. }\end{array}$ \\
\hline 2. & $\begin{array}{l}\text { Motion, Defects, } \\
\text { Transportation }\end{array}$ & $\begin{array}{l}\text { Currently, there is no provision of } \\
\text { Quality Lab on site. The Curing } \\
\text { Pond is located at the S-W corner } \\
\text { of the site, making it difficult to } \\
\text { bring samples all the way. }\end{array}$ & $\begin{array}{l}\text { A dedicated Quality Lab is } \\
\text { proposed along with the Central } \\
\text { Store, at the unloading points. } \\
\text { The Curing Pond too has been } \\
\text { moved adjacent to proposed lab }\end{array}$ \\
\hline 3. & $\begin{array}{l}\text { Transportation, } \\
\text { Motion }\end{array}$ & $\begin{array}{l}\text { The newly made Store on site is } \\
\text { adjacent to the Contractor's Site } \\
\text { Office, with very narrow access, } \\
\text { making unloading and movement } \\
\text { of material extremely tedious. }\end{array}$ & $\begin{array}{l}\text { In the proposed layout, the } \\
\text { Store has been proposed in the } \\
\text { centre of the access face, } \\
\text { making it accessible from both } \\
\text { sides of the unloading zones. }\end{array}$ \\
\hline 4. & Motion & $\begin{array}{l}\text { Labor provisions of Toilets and } \\
\text { Canteen are placed in the middle } \\
\text { of the access route to the South, } \\
\text { leading to crowding. }\end{array}$ & $\begin{array}{l}\text { Labour provisions have been } \\
\text { moved to the S-E corner, after } \\
\text { the access route to the } \\
\text { excavated site, minimizing any } \\
\text { crowding and making access } \\
\text { more convenient }\end{array}$ \\
\hline 5. & $\begin{array}{l}\text { Inventory, } \\
\text { Overproduction }\end{array}$ & $\begin{array}{l}\text { Excessive material stacking is } \\
\text { observed at multiple locations. } \\
\text { TMs are ordered in excess } \\
\text { leading to temporary inventory }\end{array}$ & $\begin{array}{l}\text { Organized layout with dedicated } \\
\text { space for storage and parking } \\
\text { enables dedicated scheduling of } \\
\text { materials to be brought on site }\end{array}$ \\
\hline 6. & $\begin{array}{l}\text { Defects, } \\
\text { Transportation }\end{array}$ & $\begin{array}{l}\text { Currently, the access face of the } \\
\text { site is devoid of any safety } \\
\text { barricading, spilling most of the } \\
\text { activities on the main road. }\end{array}$ & $\begin{array}{l}\text { To avoid such a safety hazard, } \\
\text { the proposed site barricading of } \\
4 \mathrm{~m} \text { ht. is proposed to ensure the } \\
\text { safety of passers-by. }\end{array}$ \\
\hline
\end{tabular}




\section{BENEFITS OF BIM FOR SITE LAYOUT PLANNING}

The development of the proposed site layout enabled various discussions with the project team. The visualisation offered by the model was also helpful in enabling other stakeholders and fellow colleagues to better understand the project conditions and progress, without having to visit the site. This stands to show that efficient reporting to the Client, as well as the higher management at the Contractor organisation can be enabled through model development.

Further uses of BIM were explored during this process. The intent was to understand the potential of BIM in the execution phase, for enabling a lean approach to construction activities on site. Some of these explorations have been highlighted in the following sections.

\section{DETAILING OF CONSTRUCTION ACTIVITIES}

Certain construction activities could be detailed to highlight cases of rework or failure analysis. For this purpose, a portion of the retaining wall that collapsed on site was highlighted in this model to clearly illustrate the rework strategy undertaken (Figure 6).

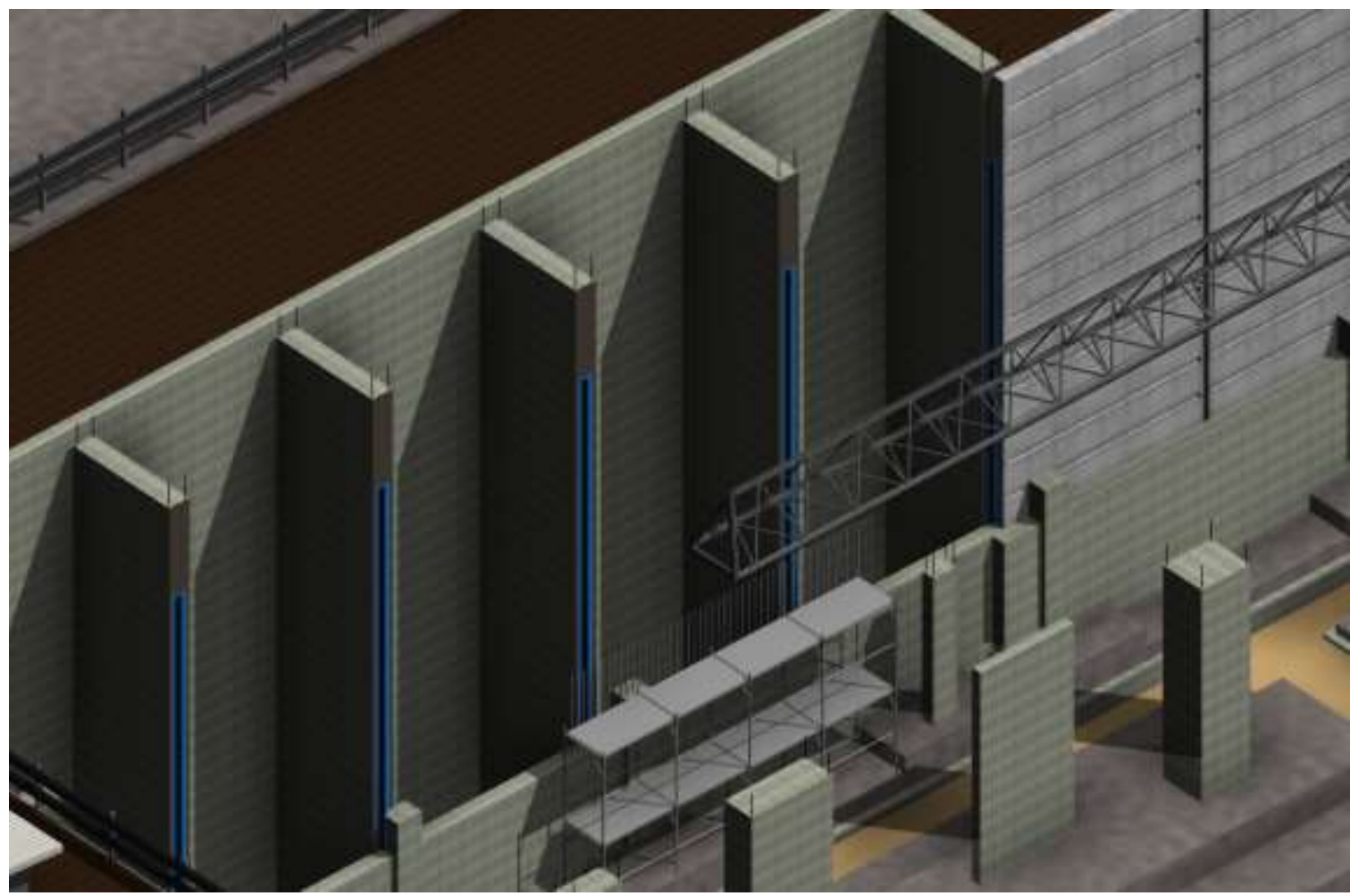

Figure 6: Detailing of construction activities

\section{EXPLORATION OF FORMWORK BEING USED ON SITE}

The model was developed to also highlight the formwork being used for columns and shear walls on site. It was realised that plug-ins are now available for use with BIM platforms to enable prior planning of formwork for the execution stage of the project (Figure 7). 

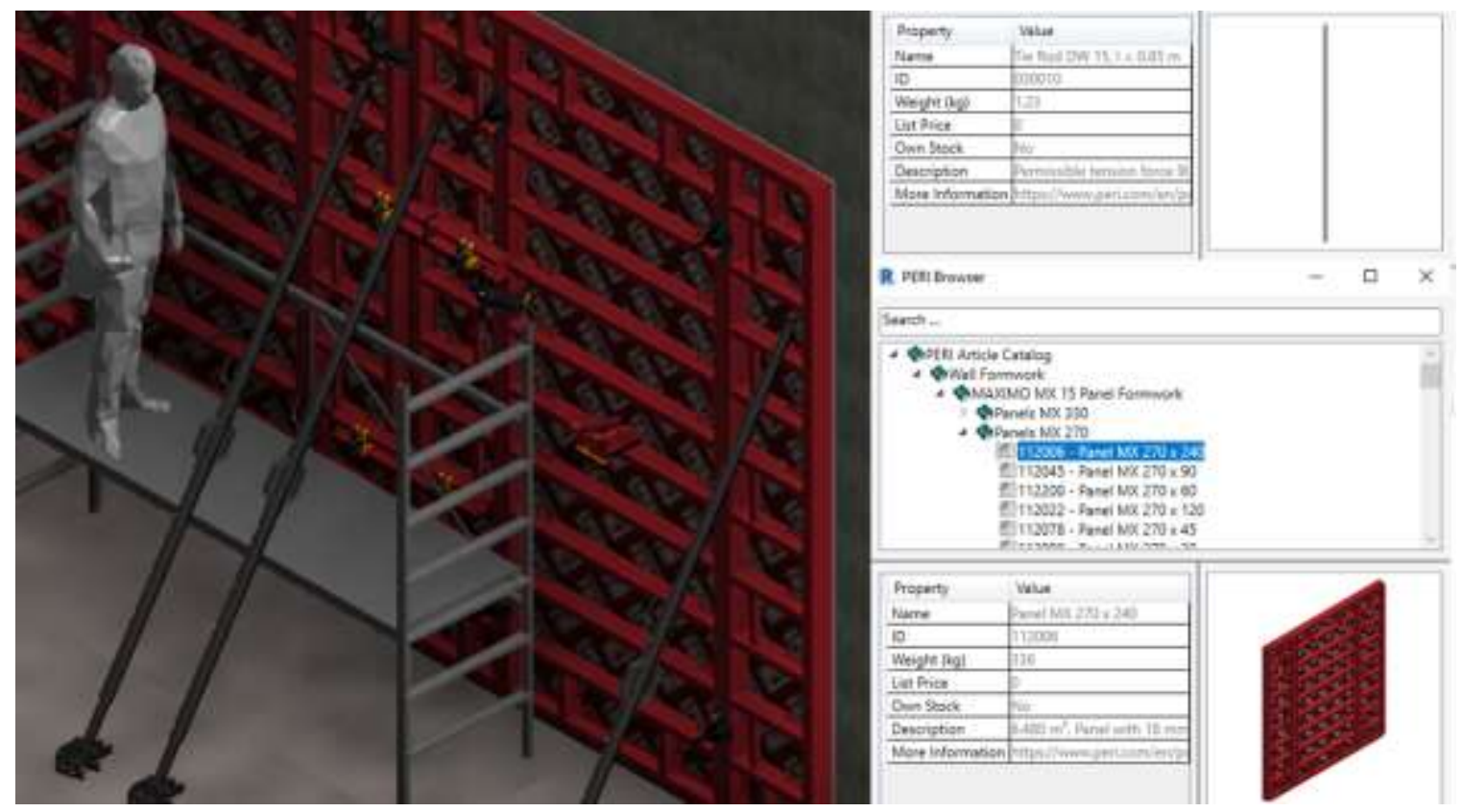

Figure 7: Formwork detailing enabled through a plug-in for BIM platform

Such involvement of formwork planning during the pre-construction stage of the project through BIM implementation can enable accurate estimation of requirement and on-time delivery of appropriate material to the site during the execution stage of the project.

\section{CONCLUSION}

The research stands to show the potential of BIM in site layout planning and monitoring of construction activities on projects. It strives to highlight that lean principles of waste minimisation and value generation can be obtained through appropriate site layout planning, leading to time and cost savings for the stakeholders of the project. The essential factor for enabling this is to have early involvement of stakeholders, driven by an IPD approach.

BIM visualisation enables collaboration between stakeholders, as has been observed by the authors through active participation with the project teams. The authors conclude that a deeper understanding of construction activities and constraints on site develops through the visualisation offered by BIM. To reinforce this, the authors further explored the potential uses of BIM in terms of detailing and rework cases observed on site. This was observed to be a critical factor for enabling discussions between project participants that are essential to the successful realisation of projects with minimum wastes. Hence, BIM can play a crucial role to enable lean delivery of projects during both pre-construction, as well as the execution phase.

BIM enables site layout planning at an early stage, through collaborative working with the Contractor and project team. Their crucial inputs for the execution activities of the project can greatly determine the timeline of activities on site. It stands to show that Target Cost (Budgets) can be achieved not just through project design changes and reviews, but also by planning the site layout appropriately for the execution of the project on site. 


\section{REFERENCES}

Bortolini, R., Shigaki, J. S.-I., \& Formoso, C. T. (2015). Site logistics planning and control using 4D modeling: A study in a lean car factory building site. IGLC, 10.

Cheng, J. C., \& Kumar, S. (2015). A BIM-based framework for Material Logistics Planning. IGLC, 10.

Dave, B., Boddy, S., \& Koskela, L. (2013). Challenges and opportunities in implementing Lean and BIM on an infrastructure project. IGLC-21, (p. 10). Fortaleza.

Fosse, R., Ballard, G., \& Fischer, M. A. (2017). Virtual design and construction: Aligning BIM and lean in practice. IGLC, (p. 8). Heraklion.

Gerber, D. J., Becerik-Gerber, B., \& Kunz, A. (2010). Building Information Modeling and Lean Construction: Technology, methodology, and advances from practice. IGLC, (p. 11). Haifa.

Guerriero, A., Kubicki, S., Berroir, F., \& Lemaire, C. (2017). BIM-enhanced collaborative smart technologies for LEAN construction processes. International Conference on Engineering, Technology and Innovation (ICE/ITMC), (p. 8).

Jin, R., Hancock, C. M., Tang, L., \& Wanatowski, D. (2017). BIM investment, returns, and risks in China's AEC industries. American Society of Civil Engineers, 13.

Koskela, L. (1992). Application of the new production philosophy to construction.

Pikas, E., Koskela, L., Sapountzis, S., Dave, B., \& Owen, R. (2011). Overview of Building Information Modeling in healthcare projects. HaCIRIC International Conference, (p. 14). Manchester.

Sacks, R., Koskela, L., Dave, B., \& Owen, R. (2010). Interaction of Lean and Building Information Modeling in Construction. Journal of Construction Engineering and Management, 13.

Singh, A. R., \& Delhi, V. S. (2018). 'Site layout planning waste' typology and its handling through AR-BIM concept: A lean approach. IGLC, 11. 
Lota, P.S., and Trivedi, J. 